\title{
Impact of local climate variability on crop model estimates in the south-east of France
}

\author{
Dominique Courault*, Françoise Ruget
}

Institut National de la Recherche Agronomique, NRA Unité Climat Sol Environnement, Site Agroparc, Domaine St Paul, 84914 Avignon, Cedex 9, France

\begin{abstract}
Most crop models use climatic data recorded from weather stations located on standard surfaces such as grass. These environmental conditions represent meso-climates typical of the region but often do not reflect the crop micro-climate. The aim of this paper is to show the effect of the environment surrounding the weather stations on the variability of climatic data and to estimate the impact of these variations on different outputs of crop models (crop cycle length, yield, irrigation and quantities of fertilizer). The crop model STICS was used with different management strategies. Simulations were performed using climatic data measured at 5 meteorological stations surrounded by different environments (wet grassland, dry area, wheat, soybean and irrigated wheat) in a small agricultural region in the south-east of France. The distances between the stations ranged from $3 \mathrm{~km}$ to a maximum of $10 \mathrm{~km}$. The region is flat and has 1 weather station of the conventional national synoptic network. The measurements show that, even at such a small regional scale, the spatial variability due to the environment surrounding a weather station is important and should be taken into account. Significant discrepancies were observed both for yield and irrigation, as well as crop cycle length, according to the climatic data considered. Differences in soil moisture produce the greatest differences in air temperature between the weather stations and, consequently, the greatest discrepancies between the outputs of the crop models.
\end{abstract}

KEY WORDS: Climate spatial variations $\cdot$ Crop model $\cdot$ Air temperature $\cdot$ Crop management

\section{INTRODUCTION}

During recent years, a large number of studies have been carried out on the effects of climate changes associated with increased levels of $\mathrm{CO}_{2}$ and other greenhouse gases on crops (Delécolle et al. 1995, Hoogenboom et al. 1995). Most of these analyses have taken into consideration climate changes calculated at a global scale.

Downscaling approaches have been developed in order to facilitate analysis of the effect of such variations on the environment on a regional scale (Hoff \& Rambal 1995). However the reverse approach ('upscaling'), which consists of monitoring the effects of local and regional landscape variations on larger-scale cli-

*E-mail: courault@avignon.inra.fr mate, should not be ignored (Barnston \& Schickedanz 1984, Segal et al. 1988, 1998). Agricultural management practices such as irrigation have been shown to modify local temperature and water vapor regimes. For instance research carried out in Israel (De Ridder \& Gallée 1998) showed that increasing irrigated surface areas in previously arid regions has led to a substantial increase in convectional precipitation during the autumn season and to a decrease in the diurnal range of temperature. Climate modification resulting from such management practices has rarely been considered in crop modeling studies.

Most crop models use climatic data recorded from weather stations located on standard surfaces such as grass. These environmental conditions represent meso-climates typical of the region but often do not reflect the crop micro-climate. If we want to estimate agricultural production for a large region, these 
'regional' weather data may be adequate. However, regional conditions may be quite misleading if they are used to estimate point-specific crop behavior and management pratices. Meteorological inputs must be appropriate to the scale of application of plant growth models (Leduc \& Holt 1987). Spatial variations of the climatic data can be important due to differences in soil moisture, roughness, vegetation type, etc. Discrepancies of 2 to $4^{\circ} \mathrm{C}$ have been observed for air temperature measured at a height of $2 \mathrm{~m}$ and in sheltered conditions between dry and irrigated zones located a few kilometers away from each other in a flat region (Seguin et al. 1982, Courault et al. 1998). These discrepancies may lead to significant variations when calculating the crop yield at a local scale. Sensitivity analyses carried out on air temperature, which is a key variable in crop models, have shown that a systematic error of $\pm 1^{\circ} \mathrm{C} \mathrm{d}^{-1}$ throughout the crop cycle can lead to errors of between 0.5 and $1 \mathrm{tha}^{-1}$ in yield estimations (Ruget et al. 1995, Monestiez et al. 2000).

The aim of our study was therefore to estimate the effect of climate variations caused by the environment surrounding the weather stations on the main outputs of crop models (yield, length of crop cycle, irrigation and nitrogen requirements). We do not present a validation of a crop model, because the crop model used in the study has already been validated with a large data set in other studies (Tayot et al. 1999, Brisson et al. 2001); in Section 3 we will present a brief summary of the main validation results obtained for the 2 crops studied. It is not an analysis of sensitivity to climatic inputs, since the climatic data used here come from several real weather stations. We want to show the possible impacts of surface land cover on climate variables and subsequently on yield.

\section{DATA}

2.1. Study area. We chose the Crau region, which is located $10 \mathrm{~km}$ from the Mediterranean Sea and $40 \mathrm{~km}$ south-east of Avignon (Fig. 1) because this region (20 $\times$ $30 \mathrm{~km}$ ) is flat with no hills nearby and agricultural surfaces vary greatly: a large dry area to the east mainly kept for grazing, and an irrigated section to the west composed of a variety of crops-grassland, rice, vegetable crops, wheat, orchards, etc. Grassland occupies a large proportion of this section and provides hay of

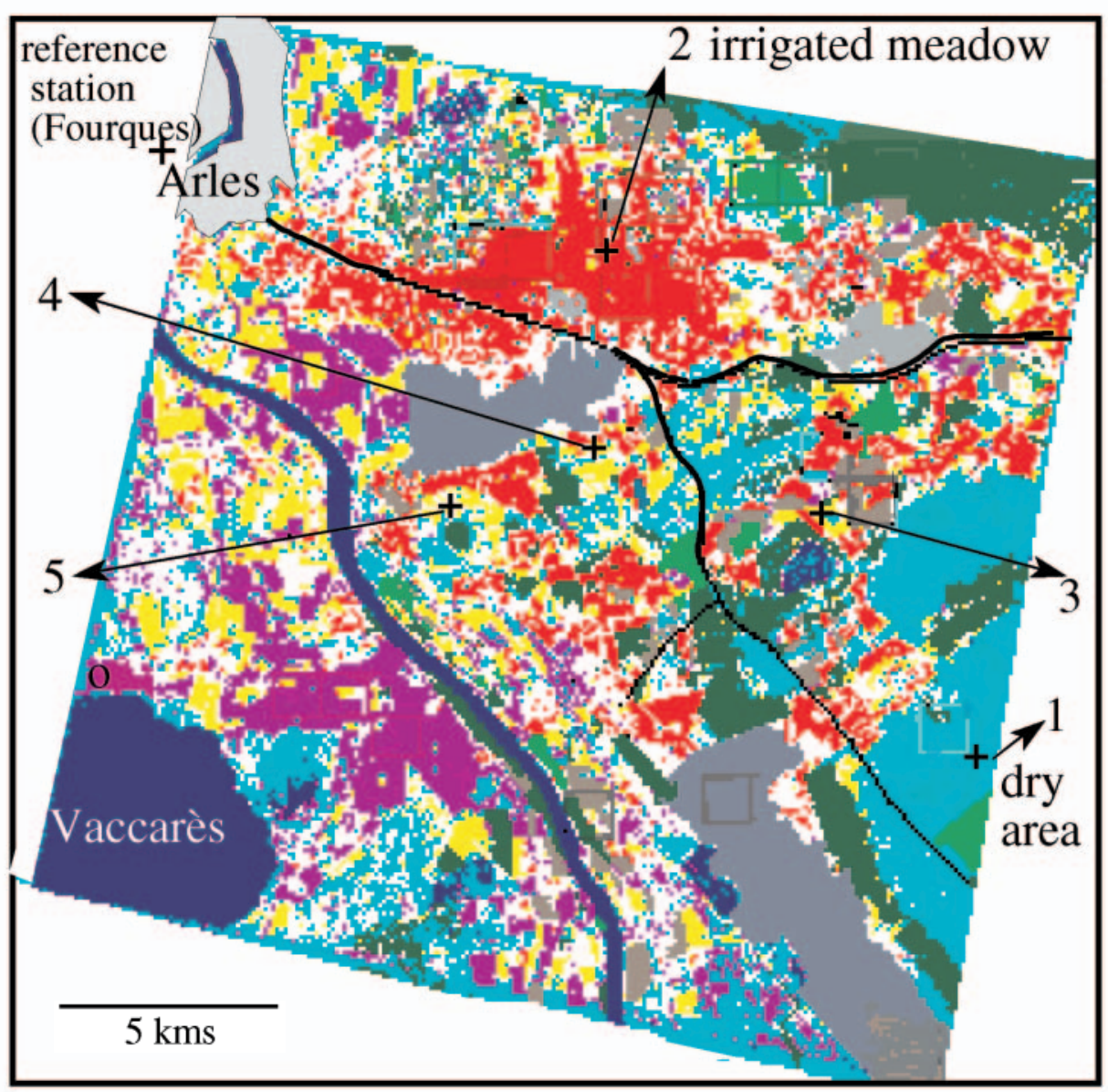

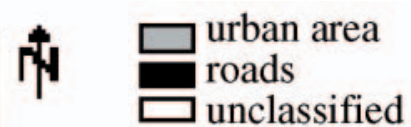

wheat
rice
vegetable
orchard
olive tree
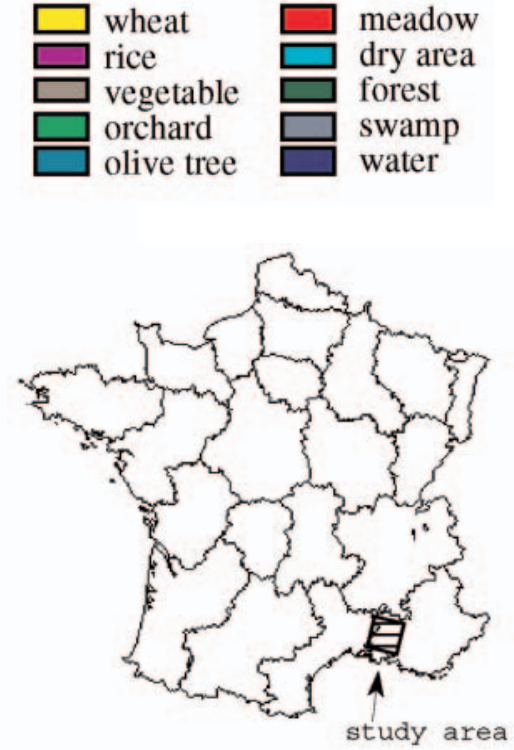

Fig. 1. Land-use map of the area studied obtained from a classification using SPOT images. The locations of the 6 meteorological stations used in this study are also shown 
great renown. (The 'Crau hay' label is exported throughout France because of its quality.) Strategic decisions such as crop rotation and irrigation schedules are made at the beginning of the crop year and are crucial for the yield because of the dry and hot climate in this region.

If we want to estimate yields for the different crops of this region, or if we want to determine the irrigation or fertilizer needs for the crop, we need climatic data as close as possible to the studied field. Typically, unless a micrometeorological station is installed in the field, there are no weather stations very close to the crop studied. Weather stations of the synoptic network are often located at distance of 10 or $30 \mathrm{~km}$ from the crop studied. For this study we used the climatic data described in the following section.

2.2. Meteorological data. 2.2.1. Conventional network stations: The national synoptic network managed by Météo-France has 2 stations near this region: the Istres station located in the military airfield in the dry area and the Salon station also in an airfield, to the north-east. No global radiation measurements exist for these 2 stations, so they cannot be used to supply data for the crop model.

AGROCLIM (Technical Service for the Study of Environmental Climatic Factors, Institut National de la Recherche Agronomique Avignon) monitors 2 stations located at close proximity to this study zone: the Fourques station near Arles surrounded by rice, wheat and grass farming plots, and the Méjanes station near the Vaccarès pond in the middle of rice fields. We selected the Fourques station as our reference station for this study because it provides reliable measurements of 11 climatic parameters at hourly time-steps including global radiation, temperature and rain. It is the station at closest proximity to our study area, unlike the Méjanes station whose environment was not specific to the Crau region.

2.2.2. Additional weather stations located on different surface environment: Since 1996 our team has established 5 meteorological stations in different agricultural environments to study the effect of the area surrounding the stations on the climatic measurements and the spatial variability of temperatures within a small agricultural region. Their locations are described in Table 1, where they are designated by the numbers shown in Fig. 1 (the distances between the stations vary from 3 to $10 \mathrm{~km}$ ). These numbers will be used here to identify the climatic data used as inputs for the crop model.

\section{CROP MODEL}

3.1. Short description of STICS. We used the crop model called 'STICS' developed by Brisson et al. (1998). It is a dynamical model with a daily time-step based on the carbon, water and nitrogen balances. Inputs take into account the climate, the soil and the cropping system. The model simulates the soil-crop behavior for $1 \mathrm{yr}$. It can simulate different crops (forage, barley, etc.); moreover it has been validated and applied to wheat and maize (Ruget et al. 1999a,b, Tayot et al. 1999, Brisson et al. 2001).

The main outputs are linked to the production (amount and quantity) and to the environment (water, carbon and nitrogen balances). The climatic data required are the global radiation, minimum and maximum temperature, precipitation, and potential (or reference) evapotranspiration. There are 7 development stages to simulate leaf area index (LAI) and grain filling. LAI development is limited by the development stages of the plants. Plant emergence determines the beginning of the leaf surface growth. From emergence to physiological maturity, the intervals between successive stages depend on species and varieties. The carbon balance is based on the radiation interception by the LAI. The transformation of the intercepted radiation into biomass depends on temperature, radiation, water and nitrogen availability. The growth rate of the crop before grain filling and during a latent period defines the grain number. The grain weight is determined by the filling duration. Grains are harvested when they are dry enough, and their dryness depends on the temperatures encountered after physiological maturity.

The soil is considered as a succession of horizontal layers, each one characterized by its water content, 
mineral nitrogen and organic nitrogen amounts. The roots are classified according to their length and density in each layer. The part of the model simulating the water balance computes the plant transpiration, the soil evaporation and indices related to the water status of the plants and soil, which can reduce the main physiological functions when there is stress. (Soil evaporation concerns only the first surface layer.)

The main field practices must be defined as the following input data: sowing date, plant density, and irrigation or nitrogen amounts supplied during the cycle. The different thresholds in degree-days are also entered for each species and variety to define the main phenological stage. These stages correspond to changes in trophic or morphological strategy of the crop that influence the evolution of the LAI or grain filling. Three indices (varying from 0 to 1 ) are computed in the water and nitrogen balance, which reduce the leaf growth and the radiation-use efficiency when nutrition is limited. Irrigation and nitrogen amounts can also be computed by the model if thresholds are established for these indices.

3.2. Model validation. In this section, we present a short review of the main validation results obtained for wheat and maize (for more details see Brisson et al. 2001).

The validation was carried out for the above-ground biomass, the yield and yield components, flowering and maturity dates, nitrogen contents in the plants and grain, and water and nitrogen contents in the soil. A wide range of situations has been studied both for wheat and maize: different types of soils, climate, varieties, etc. (22 for wheat cultivation, 25 for maize, 14 for bare soil, corresponding to periods between 2 crops). The degree-days (cumulative temperature from the sowing date) $\sum T$ varied from 1741 to 2210 for maize and from 2250 to 3223 for wheat, representing most of the climatic conditions encountered from the north to the south of France. The observed yields of this data set varied from 29 to $115 \mathrm{q} \mathrm{ha}^{-1}$ for wheat and from 3 to $135 \mathrm{q} \mathrm{ha}^{-1}$ for maize. Table 2 presents the relative mean square error (RMSE), which provides a value for the model's prediction giving a lot of weight to high errors, whereas MD is the mean deviation giving the same weight to all errors (in this table [derived from

Table 2. Statistical criteria for assessing the performance of the STICS model (RMSE: relative mean square error, MD: mean deviation) according to Table 6 in Brisson et al. (2001)

\begin{tabular}{|lcccc|}
\hline $\begin{array}{c}\text { Wheat yield } \\
(\mathrm{q} \mathrm{ha})\end{array}$ & $\begin{array}{c}\text { Maize yield } \\
(\mathrm{q} \mathrm{ha})\end{array}$ & $\begin{array}{c}\text { Final soil water } \\
(\mathrm{mm})\end{array}$ & $\begin{array}{c}\text { Final soil nitrogen } \\
\left(\mathrm{kg} \mathrm{ha}^{-1}\right)\end{array}$ \\
\hline RMSE & 16.03 & 24.49 & 28.27 & 40.88 \\
MD & 4.02 & 0.75 & 17.7 & 23.57 \\
\hline
\end{tabular}

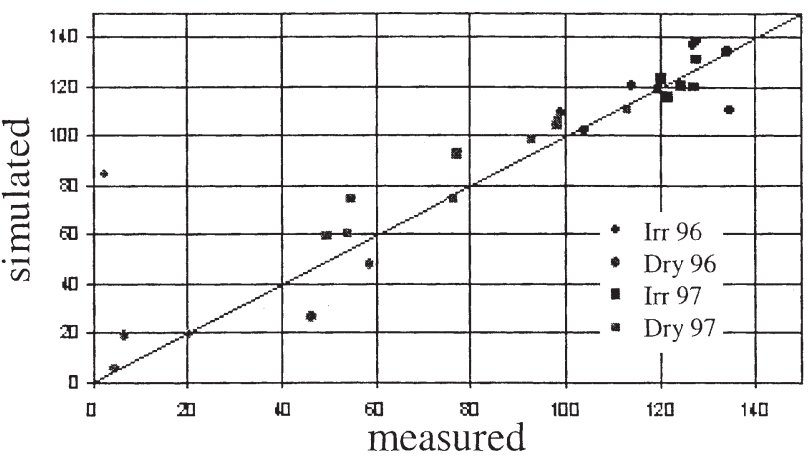

Fig. 2. Comparison of the grain of dry matter (MSG) simulated by STICS and measured on different sites in the Poitou-Charente region for maize for 2 conditions: dry and irrigated (from Tayot et al. 1999)

Brisson et al. 2001] we have kept only the output variables which were used in our study). It appears that the behavior of the 2 crops is satisfactory for yield estimation, with quite similar performance but slightly better results for wheat. Fig. 2 shows that the range of yield simulated for maize is very large. The prediction for the amount of water remaining in the soil at the end of simulation is fairly accurate. The results are less satisfactory for the nitrogen in the soil, mainly due to the overestimation of the consumption by the plant. More variables, such as the LAI, have been investigated in the paper of Brisson et al. (2001), which allows one to understand the model's results and to propose some modifications. This model is continually evolving.

\section{METHODS}

In this study, we used STICS both on wheat and irrigated maize to analyze the impact of spatial variability of climatic data caused by the environment on the yield, irrigation and nitrogen amounts. The irrigation and nitrogen amounts were computed automatically by the model, attaching thresholds to the indices previously defined.

Wheat crops account for a large proportion of the Crau region (15 to $20 \%$ of the surface area). The cycle is long (winter, spring and the beginning of summer) and usually without irrigation. Numerous decisions have to be made at regular intervals throughout the cycle based on the development of the crop and on climate variability. The maize crop cycle is shorter (end of spring and summer) and requires not inconsiderable amounts of irrigation, especially in southern France.

The water and nitrogen supply vary during the cycle in our simulations. The nitrogen is supplied when the maximum nitro- 
gen stress levels have been reached. The maximum is given by an index (set at 0.8 for our study) which is defined as the ratio of the actual concentration to the critical concentration of nitrogen in the plant. The quantity then added automatically by the model is $50 \mathrm{~kg} \mathrm{ha}^{-1}$.

The water supply criterion in the STICS model is based on a threshold, calculated as the ratio of actual evapotranspiration (or accessible water) to potential evaporation (or requirements)-(AET/PET). For our simulations, it was set at 0.5 , allowing for water stress. The maximal dose for each supply can be limited (the dose was fixed at $40 \mathrm{~mm}$ in our case).

We used the crop model with input climatic data from the 6 weather stations described in Section 2 (located in different environments, see Fig. 1 and Table 1). The air temperature (usually expressed as a sum of degreedays in the crop model) is among the most important variables in working out the different development phases of these crops. Global radiation is an important input in the crop model for biomass elaboration.

Among the outputs studied, yield signifies grain yield at $0 \%$ moisture. The harvesting date is set as the point when the grains are sufficiently dry, their moisture content depending on the temperature change since the maturing stage. Table 3 summarizes the different simulations performed with the model. We included in the model field practices similar to those in the Crau. In order to take into account the spatial variability of the sowing date, we have chosen 2 sowing dates for each crop.

\section{RESULTS}

\subsection{Regional temperature and precipitation variation}

Fig. 3a,b shows cumulative rainfall during 1996 and 1997 for the different stations in La Crau and for
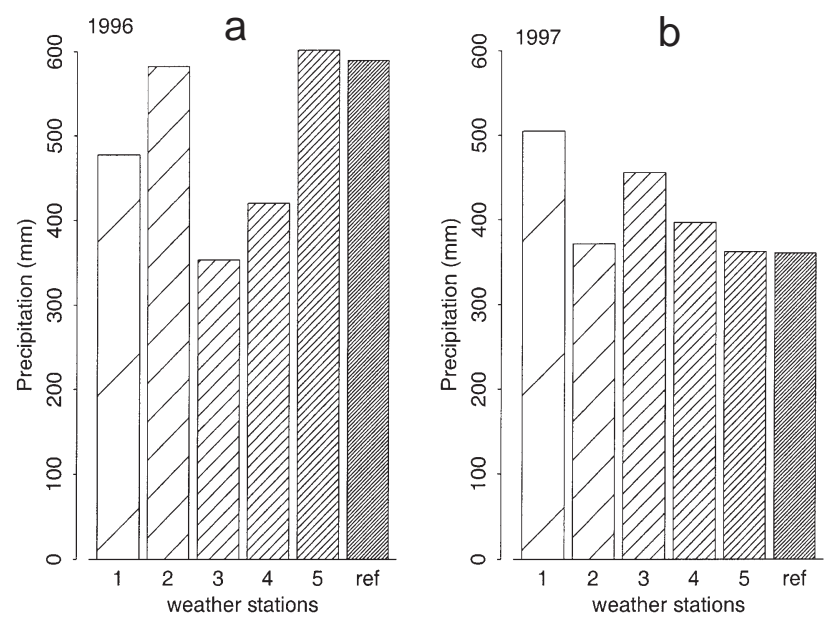

Fig. 3. Comparison of precipitation observed at the different Crau stations and the Fourques station for (a) 1996 and (b) 1997

the reference station in Fourques (described in Table 1). Although the region is flat and the stations are in close proximity to each other (certain stations such as Stns 4 and 5 are barely $3 \mathrm{~km}$ apart), the variability in precipitation at this small agricultural region scale is great. The maximal discrepancy observed between 2 stations was $248 \mathrm{~mm}$ in 1996 and $143 \mathrm{~mm}$ in 1997.

The variability between years is important too. Paradoxically the station located in the 'dry' Crau area (Stn 1) received the most rainfall in 1997. This is due to a single local storm on 7 October, which supplied over $60 \mathrm{~mm}$ of water in a single day.

Daily air temperatures (minimal and maximal) also varied greatly between stations, due mainly to the influence of the environment surrounding the station (Seguin et al. 1982, Anderson et al. 1997, Courault et al. 1997). Differences in water status of the surfaces

Table 3. The different strategies used with the STICS model. (yd: yield, N: nitrogen, RU: useful reserve, lg cy: length of crop cycle). Maize: 2 field practices ( 2 sowing dates) $\times 6$ climates over $2 \mathrm{yr}=24$ simulations; wheat: 2 technical practices ( 2 sowing dates) $\times 6$ climates $=12$ simulations

\begin{tabular}{|c|c|c|}
\hline & Maize & Wheat \\
\hline Variety & 1: PACTOL & 1: ARCOUR \\
\hline Sowing dates & 2: 13 Apr, 1 May in 1996 and 1997 & 2: 13 Nov, 29 Nov \\
\hline Soil & $\begin{array}{l}\text { 1.7m soil depth, } \\
\text { RU: } 200 \mathrm{~mm}\end{array}$ & $\begin{array}{l}50 \mathrm{~cm} \text { soil depth } \\
\text { RU: } 100 \mathrm{~mm}\end{array}$ \\
\hline Water supply & $\begin{array}{l}\text { Optimized following the stress index set at } 0.5 \\
\text { (max. dose: } 40 \mathrm{~mm} \text { ) }\end{array}$ & Fixed $(0)$ \\
\hline N supply & $\begin{array}{l}\text { Optimized following the nitrogen stress index } \\
\text { set at } 0.8 \text { (max. dose: } 50 \mathrm{~kg} \mathrm{ha}^{-1} \text { ) }\end{array}$ & $\begin{array}{l}\text { Optimized following the nitrogen stress index set at } 0.8 \\
\left(\max \text { dose: } 50 \mathrm{~kg} \mathrm{ha}^{-1} \text { ) }\right.\end{array}$ \\
\hline Outputs studied & $\begin{array}{l}\text { yd, cy lg, water and } N \text { supplies, } N \text { absorbed, } \\
\text { leached and remaining in the soil }\end{array}$ & yd, cy lg, $\mathrm{N}$ leached and remaining at the end of cycle \\
\hline
\end{tabular}



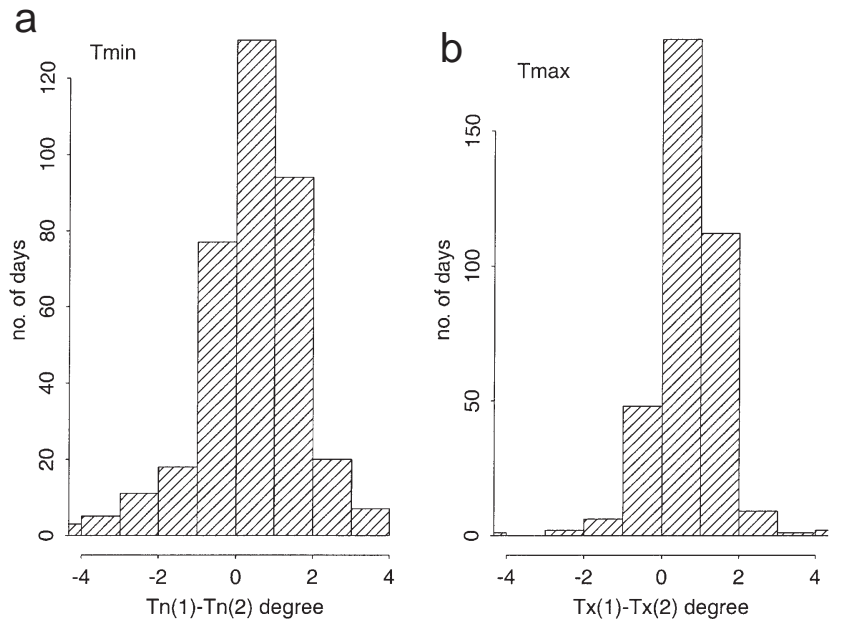

Fig. 4. Discrepancies in temperature observed between meteorological stations 1 and 2, corresponding to dry and irrigated grassland conditions respectively, (a) for daily minimal values,

(b) for daily maximal values in 1997

surrounding the meteorological stations due to both spatial distribution of precipitation and to differences in soil and vegetation types can lead to differences in temperature of 2 to $4^{\circ} \mathrm{C}$ for some days. These discrepancies between stations can vary depending on the general atmospheric conditions (an increase in wind speed, for example, tends to reduce the discrepancies between stations and homogenize the temperatures throughout the area). Fig. $4 \mathrm{a}, \mathrm{b}$ shows the discrepancies observed between the most different stations: Stn 1 (located in dry grassland) and Stn 2 (irrigated grassland) in terms of (a) minimal and (b) maximal temperatures in 1997 . Over $30 \%$ of the discrepancies were of $>1^{\circ} \mathrm{C}$. These discrepancies, as will be seen in the following section, are far from negligible for crop model outputs.

\subsection{Influence of regional variability of crop model estimates}

\subsubsection{Wheat}

Fig. 5 gives the results obtained for the wheat sowed on 13 November 1996 using the different climatic series from the Crau region. Discrepancies of up to $6 \mathrm{q}$ $\mathrm{ha}^{-1}$ can be observed between the yields (Fig. 5a), which represents $39 \%$ of the yield average. The yield values are low (remember that these values correspond to the estimation of the grain yield at $0 \%$ moisture for wheat without irrigation). They are similar to the values given by the farmers in the region (for example, the yield observed near Stn 3 was $18 \mathrm{q} \mathrm{ha}^{-1}$ versus $15.5 \mathrm{q} \mathrm{ha}^{-1}$ estimated by STICS). The difference between the yield observed and that simulated can be explained by several factors: we did not have all the information about the field practices (e.g., the exact sowing date, the sowing density and the different intervention dates for fertilizer use) to correctly program the model, only general information on the wheat crop and the yield. Most wheat fields are not irrigated in this region; but the climate is generally hot and dry and the water reserve of the soils low (50 to $100 \mathrm{~mm}$ ). Compared to other crops, however, development of winter wheat was possible and the yields are not negligible.

We observed a difference of $4 \mathrm{~d}$ for the harvesting date between the stations (Fig. 5b). For the warmest climatic conditions (Stn 1), the season length is shorter. These results give the same trend as the results obtained in studies dealing with global warming (due to the greenhouse effect) on winter wheat for different regions in France (Delécolle et al. 1995).

The discrepancies observed between stations for the nitrogen absorbed by the plant during the cycle

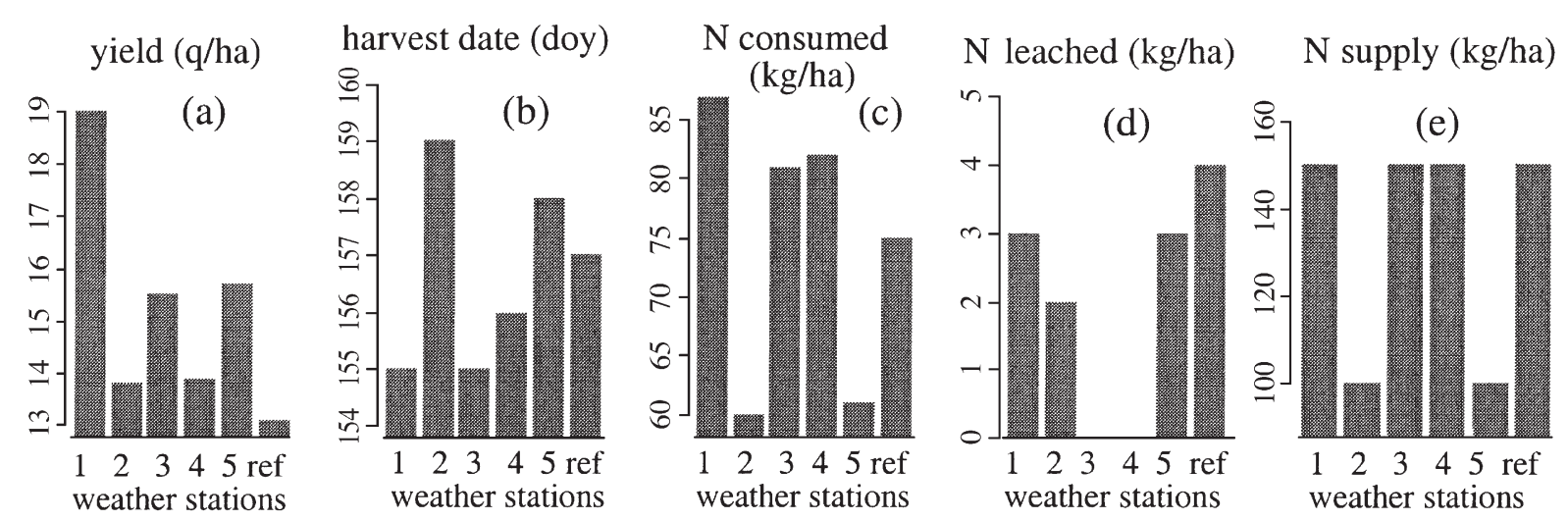

Fig. 5. Main outputs of STICS model applied to hard wheat sowed on 13 November 1996 according to the different climatic data recorded in La Crau region (a) yield, (b) harvesting date (doy: day of year), (c) nitrogen absorbed by the crop, (d) nitrogen leached in the soil and (e) nitrogen added to the crop during the cycle, computed automatically by STICS according to the nitrogen index 
(Fig. $5 \mathrm{c}$ ) are $37 \mathrm{~kg} \mathrm{ha}^{-1}$ (36\% of variation compared to the mean value absorbed). The nitrogen quantity absorbed by the crop and that leached in the soil depend on different factors: on the quantity added to the crop in the cycle (Fig. 5e) and on yield (the crop having produced the most biomass consumed the most nitrogen during the cycle and therefore left most residues at the end of harvesting). The amount of nitrogen leached also depends on the rainfall quantity. Two stations ( 3 and 4) show no nitrogen leached, because all of it was consumed during the cycle. Compared to the other stations, they received less rainfall during the period between November and June $(279 \mathrm{~mm}$ for Stn 3 versus $418 \mathrm{~mm}$ for the reference station Fourques, for example), which explains the differences observed.

\subsubsection{Maize}

In terms of yield and length of cycle, the effects of the regional climatic variations are more pronounced for maize than they are for wheat. This could be due to a number of factors, especially the seasonal differences among weather stations. The maize cycle is shorter: our simulations started on 13 April and ended in the middle of September; it is the period where the air temperature differences between stations are the highest, reaching up to $2^{\circ} \mathrm{C}$. The maximal difference observed between stations was 450 degree-days for the maize cycle in 1996 and 126 degree-days in 1997, whereas for wheat the differences observed were 75 degree-days for the period 1996-97 (the simulations started in November and ended at the beginning of June).

The simulations carried out with STICS on maize show discrepancies in yield of up to $38 \mathrm{q} \mathrm{ha}^{-1}$ and up to $10 \mathrm{~d}$ for the harvesting date in 1996. The sowing date (13 April 1997 or 1 May 1997) has little influence on discrepancies among harvesting dates (Fig. 6c), but modifies the discrepancies observed in yield (Fig. 6a,b): from 12 to $22 \mathrm{q} \mathrm{ha}^{-1}$ (i.e., 13 and $24 \%$ compared to the yield average). Maize sowed earlier under certain climatic conditions (favorable radiation and temperature, in the case of Stn 1, e.g., which is the warmest station) can, in fact, grow better and gives higher yield (Fig. 6a). The results show the same trend as those obtained in other studies on climate change (Delécolle et al. 1995); however, the quantity of the regional maize yield variability is greater $\left(38 \mathrm{q} \mathrm{ha}^{-1}\right)$ than the yield variability estimated under climate change, which varies around $20 \%$ of yield according to the climatic scenario used.

\subsection{Influence of regional climate variations on nitrogen requirements}

The nitrogen requirements for an optimal yield also varied greatly depending on the climatic data used for wheat and maize (Table 4). The nitrogen amounts are computed automatically by STICS according to a threshold fixed at 0.8 (each quantity added being $50 \mathrm{~kg} \mathrm{ha}^{-1}$, see Section 4). The quantity computed in this way for wheat estimated at $200 \mathrm{~kg}$ $\mathrm{ha}^{-1}$ was near the real level of nitrogen actually used by the farmer (quantity applied by the farmer to the field near this station: $170 \mathrm{~kg} \mathrm{ha}^{-1}$ ). The differences observed among stations are up to $100 \mathrm{~kg} \mathrm{ha}^{-1}$ for wheat.

The sowing date had little influence on the discrepancies observed for the maize from one station to another for nitrogen supply during the cycle (Table 4). These differences varied by up to $250 \mathrm{~kg} \mathrm{ha}^{-1}$ according to climatic data used in the crop model.
Fig. 6. $(\mathrm{a}, \mathrm{b})$ Yields and (c) harvest dates simulated with the STICS model for maize sown on 2 different dates: 13 April 1997 and 1 May 1997 , using as inputs the climatic data from the 5 Crau stations and the reference station at Fourques
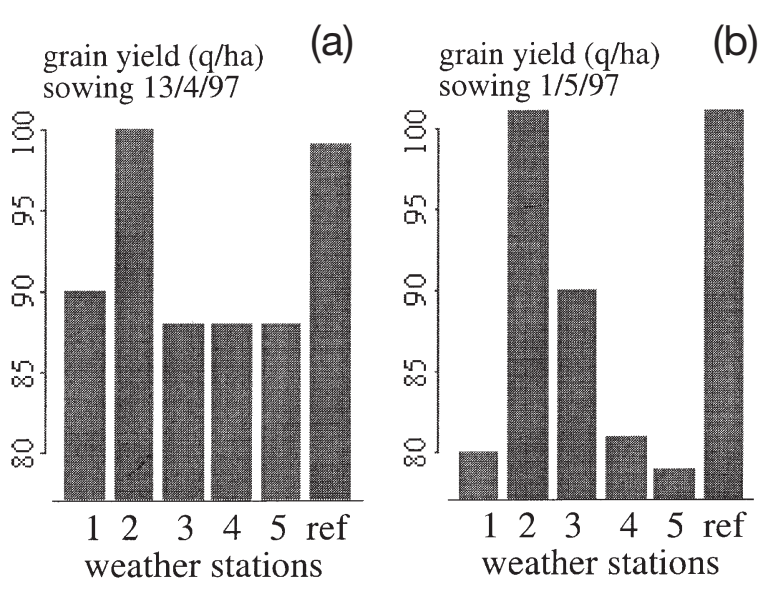

(c)

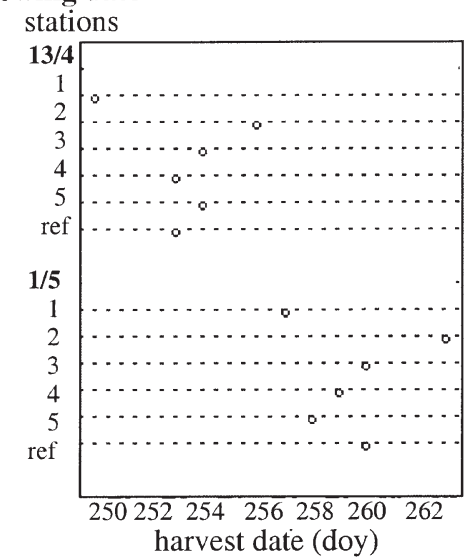


Table 4 Nitrogen supply simulated by STICS for (a) maize sown on 2 different dates and (b) winter wheat sown on 13 November 1996

\begin{tabular}{|c|c|c|c|}
\hline \multirow[t]{2}{*}{ Stn } & \multicolumn{3}{|c|}{$\mathrm{N}$ supply $\left(\mathrm{kg} \mathrm{ha}^{-1}\right)$} \\
\hline & 13 Apr 1997 & & 1 May 1997 \\
\hline \multicolumn{4}{|l|}{ (a) Maize } \\
\hline 1 & 300 & & 300 \\
\hline 2 & 200 & & 250 \\
\hline 3 & 400 & & 450 \\
\hline 4 & 350 & & 400 \\
\hline 5 & 350 & & 400 \\
\hline Ref. (Fourques) & 250 & & 200 \\
\hline Max. diff. & 200 & & 250 \\
\hline \multicolumn{4}{|l|}{ (b) Wheat } \\
\hline 1 & & 300 & \\
\hline 2 & & 250 & \\
\hline 3 & & 300 & \\
\hline 4 & & 300 & \\
\hline 5 & & 200 & \\
\hline Ref. (Fourques) & & 300 & \\
\hline Max. diff. & & 100 & \\
\hline
\end{tabular}

\subsection{Influence of regional climate variations on irrigation}

Fig. 7 shows the different amounts of water supplied to maize calculated with the STICS model depending on the climates used for 1996 and 1997. The maximal discrepancies observed between stations were $72 \mathrm{~mm}$ of water supplied in 1996 and $160 \mathrm{~mm}$ in 1997. These quantities are correlated to rainfall differences between stations. As the year 1997 was, on average, dryer $(408 \mathrm{~mm})$ than 1996 (503 mm), the average amount of irrigation in the 6 stations was, naturally, greater in 1997 than in 1996.

Of course the different model outputs (yield, irrigation and nitrogen levels) are linked by the environmental conditions at each site. These factors are interrelated in that the more nitrogen, the more biomass, and the more biomass, the greater the irrigation demand.
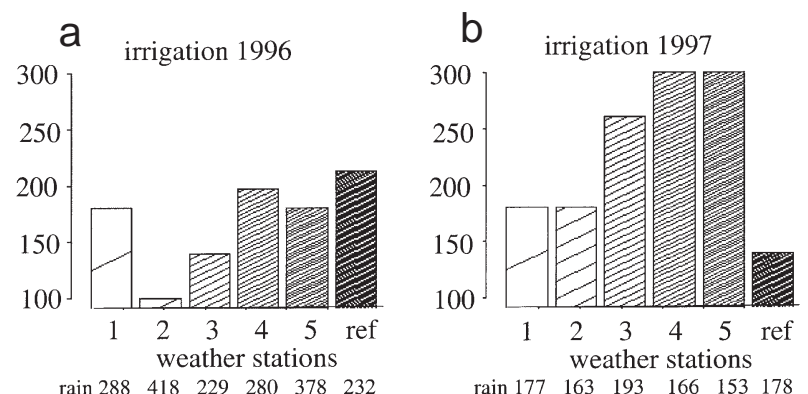

Fig. 7. Amounts of irrigation simulated with STICS for maize sown on (a) 30 April 1996 and (b) 1 May 1997, using climatic data from the $5 \mathrm{Crau}$ and Fourques stations (the cumulative rain for the crop cycle is noted for each station)

\section{DISCUSSION}

\subsection{Discrepancies observed with regard to the sensitivity of the crop model}

One issue is whether the discrepancies observed between the model outputs due to the climatic inputs are significant considering the errors due to the model itself. Although it is difficult to accurately assess errors in the variables studied, we can assume that the errors were the same from one weather station to another. This would mean that they are not related to initial meteorological conditions but to simplifications made in the model in order to represent crop development. Of course, this assumption is debatable, as certain correlation coefficients established more or less empirically may depend on the meteorological observations used. In this case, it is difficult to assess the effective role of the environment in these relationships. Nevertheless, we can state that the discrepancies due to variability in the climatic data used as model inputs are large.

The accuracy of the yields calculated using STICS is estimated at $16 \mathrm{q} \mathrm{ha}^{-1}$ for wheat and $24 \mathrm{q} \mathrm{ha}^{-1}$ for maize (Table 2; Ruget et al. 1999, Tayot et al. 1999, Brisson et al. 2001). The maximum discrepancies observed among weather stations were above these values and are therefore significant, which means that the environment surrounding the meteorological stations must be taken into account in order to assess the impact of cultural practices on yield as well as on costs (water and nitrogen). Until now, the aim has generally been to maximize yield, but today we are required to respect a number of constraints such as reducing the number of interventions on a plot (irrigation or application of fertilizer) or ensuring that the nitrogen remaining in the soil for the following crop is sufficient and does not exceed the critical thresholds for ground water pollution. The strategic choices to be made concerning practices carried out on the plots vary depending on the climate considered.

\subsection{Testing the sensitivity of STICS to daily air temperature}

In order to more accurately assess the importance of air temperature and its impact on crop model outputs, we compared the main STICS model outputs applied to irrigated maize for sets of temperatures ranging from -2 to $+2^{\circ} \mathrm{C}$ daily throughout the year, or only for the summer period (June to September, a period when differences in temperature are often greatest among meteorological stations). We only studied 1 year (1997), taking into consideration climatic data from Stn 2, 
located in wet grassland, and 1 sowing date-1 May 1997. Using this climatic series, we added or subtracted a constant value to or from the daily minimal or maximal temperatures every day or during the 3 summer months. Table 5 shows the simulated discrepancies for each of the cases studied compared to the normal climatic conditions observed (0) for the main outputs of the STICS model. The results show that if temperature is systematically overestimated by $0.5^{\circ} \mathrm{C}$ each day, then production is underestimated by $10 \mathrm{q}$ $\mathrm{ha}^{-1}$ and the crop cycle is shortened.

Considering the results of simulations in which differences in temperature apply only to the summer period, the discrepancies observed compared to the normal climatic series are smaller but remain significant.

These results regarding the sensitivity of the model to air temperature need further simulations taking into consideration many different years and sowing dates, but they provide the same trends as those studies carried out on the effects of global changes on crops (Delécolle et al. 1995). The scenarios under doubled $\mathrm{CO}_{2}$ conditions lead to an increase in average air temperature of between 0.5 and 1 or $2^{\circ} \mathrm{C}$ depending on the models. Numerous studies on the impact of climate changes have shown a reduction of crop cycle length and yield that is more or less important, depending on the crop variety.

The discrepancies given in Table 5 are high because the error was accumulated daily. Among the different climatic series used in the Crau region, the discrepancies in air temperature observed between stations varied from one day to another and depended on the water content of the surfaces but also on the general atmospheric conditions. On certain summer days, these discrepancies were able to reach values as high as 2 to $4^{\circ} \mathrm{C}$ between dry and irrigated areas, which underlines the importance of selecting the climatic data to be entered into the crop models carefully, and ensuring that it is representative.

\section{CONCLUSION}

Spatial variability of climatic data due to the environment of the weather station must be taken into account when considering cultural practices and managing inputs correctly (water and nitrogen) so as to limit costs and the risks of pollution. An analysis of the different conditions of the surfaces surrounding the meteorological stations showed that the influence of water status was one of the main factors involved in air temperature variation in our flat Crau region. These differences compared to a conventional station from the synoptic network led to significant differences in
Table 5. Discrepancies between simulations using the reference climatic data and simulations running with climatic data with constant values added to or subtracted from air temperature throughout the year or (in parenthesis) only during the summer period. (doy: day of the year)

\begin{tabular}{|lcc|}
\hline$\Delta T\left({ }^{\circ} \mathrm{C}\right)$ & $\Delta$ yield $\left(\mathrm{q} \mathrm{ha}^{-1}\right)$ & $\Delta$ harvest date (doy) \\
\hline-2 & 28 & 28 \\
-1 & $15(15)$ & $11(7)$ \\
-0.7 & 8 & 8 \\
-0.5 & $6(3)$ & $6(3)$ \\
0 & 0 & 0 \\
0.5 & $-10(-6)$ & $-6(-3)$ \\
0.7 & -11 & -7 \\
1 & $-21(-17)$ & $-13(-7)$ \\
2 & -29 & -18 \\
\hline
\end{tabular}

yield calculations of as high as $38 \mathrm{q} \mathrm{ha}^{-1}$ and differences in harvesting date of up to $17 \mathrm{~d}$.

These results also pose a problem in terms of the climatic data to be used for adjusting the crop model parameters. Currently this adjustment is done using standard meteorological data (conventional network) or with local data obtained from measurements taken on experimental plots, and they are often used to simulate all sorts of data. It would therefore appear necessary to carefully consider coherence between climatic data before adjustment (calibration) and prediction. In practice, this is problematic because not all the data are available everywhere, whether for adjustment purposes or prediction purposes. A methodology allowing one to recover the micro-climatic conditions of plots following certain assumptions (regional homogeneity and no transfer by advection) provides an initial solution to this problem (Brown \& Gillespie 1991, Courault et al. 1998, Courault et al. 1999). If we want to take into account the effect of the spatial organization of plots in the landscape, and the lateral exchanges between surfaces, an atmospheric 3-D model is necessary. Changes in the land use can then be simulated in order to study the retroactive effects of crops on the climate. These studies will allow us to improve our understanding of interactions between cultivated surfaces and the atmosphere and to better evaluate the agronomic consequences of climate changes induced by environmental surfaces.

Acknowledgements. We thank Anne-Marie Wall (INRA translation Jouy en Josas) for her help with the English translation. The authors are also grateful for useful comments made by anonymous reviewers. This study was funded in part by the project ECOSPACE from INRA and by the ECLAT project of the Environment Ministry. Thanks to the different project's participants, in particular to D. Leenhard, F. Garcia, A. Olioso (INRA) and to the farmers of 'La Crau' for their availability. 


\section{LITERATURE CITED}

Anderson MC, Norman JM, Diak GR, Kustas WP, Mecikalski JR (1997) A two-source time integrated model for estimating surface fluxes using thermal infrared remote sensing. Remote Sensing Environ 60:195-216

Barnston AG, Schickeldanz PT (1984) The effect of irrigation on warm season precipitation in the southern Great Plains. J Clim Appl Meteorol 23(6):865-888

Brisson N and 17 others (1998) STICS: a generic model for the simulation of crops and their water and nitrogen balances. I. Theory and parametrization applied to wheat and maize. Agronomie 18:311-346

Brisson N, Ruget F, Gate P, Lorgeou J, and 8 others (2001) STICS: a generic model for simulating crops and their water and nitrogen balances. II. Model validation for wheat and corn. Agronomie (in press)

Brown RD, Gillepsie TJ (1991) Estimating crop top microclimates from weather station data. Atmos Ocean 29(1): $110-132$

Courault D, Cauchi P, Clastre P, Bloeser B (1997) Analyse des variations spatiales de la température de l'air en fonction de l'occupation de surface. Photo-interprétation 34(3-4): 19-32

Courault D, Clastre P, Cauchi P, Delécolle R (1998) Analysis of spatial variability of air temperature at regional scale using remote sensing data and a SVAT model. Proc 1st Int Conf Geospatial Inform Agric For Environmental Research Institute of Michigan, 1-3 June 1998, Lake Buena Vista, FL II:149-156

Courault D, Garcia F, Ruget F, Leenhardt D (1999) Impact of spatial climatic variations on the outputs of crop models applied at regional scale. Int Symp Modelling Cropping Systems, Proc European Society of Agronomy, Lleida, Spain, 21-24 June 1999, p 163-164

Delécolle R, Ruget F, Ripoche D (1995) Possible effects of climate change on wheat and maize crops in France. American Society of Agronomy, climate change and agriculture: analysis of potential international impacts. Am Soc Agron 59:241-257

De Ridder K, Gallée H (1998) Land surface induced regional climate change in southern Israel. J Appl Meteorol 37: 1470-1485

Hoff C, Rambal S (1995) Régionalisation des effets clima-

Editorial responsibility: Gerd Esser,

Gießen, Germany tiques, impacts sur les écosystèmes méditerranéens. Programme ECLAT, Ministère de l'environnement, MétéoFrance, Toulouse, p 139-161

Hoogenboom G, Tsuji GY, Pickering NB, Curry RB, Jones JW, Singh W, Godwin JC (1995) Decision support system to study climate change impacts on crop production. Am Soc Agron 59:51-75

Leduc SK, Holt DA (1987) The scale problem: modeling plant yield over time and space. In: Wisiol $\mathrm{K}$, Hesketh J (eds) Plant growth modeling for resource management. Vol 1. Current models and methods, Chap 6. CRC Press, Boca Raton, FL, p 125-135

Monestiez P, Courault D, Allard D, Ruget F (2000) Spatial interpolation of air temperature using environmental context: application to crop model. Environ Ecol Stat (in press)

Ruget F, Nicoullaud B, Lorgeou J, Brisson N, Gate P, Ripoche D, King D, Delécolle R, Daroussin J, Ngongo L, Clastre P (1995) Délimitation de zones aux potentialités équivalentes en France et dans la communauté européenne pour optimiser les réseaux d'expérimentation des variétés. In: Ruget F (ed) Blé et maïs. INRA, Avignon

Ruget F, Duru M, Gastal F (1999a) Adaptation of an annual crop model (STICS) to a perennial crop: grassland. Int Symp Modelling Cropping Systems, Lleida, 21-23 June 1999. European Society of Agronomy, p 111-112

Ruget F, Delécolle R, Tchamitchian M (1999b) Sensitivity analysis of a crop model: use of a two different methods. Int Symp Modelling Cropping Systems, Lleida, 21-23 June 1999, p 244-245

Segal M, Avissar R, McCumber MC, Pielke RA (1988) Evaluation of vegetation effects on the generation and modification of mesoscale circulations. J Atmos Sci 45(16): 2269-2292

Segal M, Pan Z, Turner RW, Takle ES (1998) On the potential impact of irrigated areas in North America on summer rainfall caused by large-scale systems. J Appl Meteorol 37:325-331

Seguin B, Baelz S, Monget JM, Petit V (1982) Utilisation de la thermographie IR pour l'estimation de l'évaporation régionale. II: Résultats obtenus partir de données satellites. Agronomie 2(2):113-118

Tayot X, Ruget F, Bouthier A, Lorgeou J, Lacroix B, Pons Y (1999) Stics en Poitou-Charentes: calibration et validation sur maïs et sorgho. Perspectives Agric 242:86-95

Submitted: August 4, 1999; Accepted: April 17, 2001

Proofs received from author(s): September 27, 2001 